\title{
A REPRESENTAÇÃO SOCIAL DE ALUNOS DE ESCOLAS DA REDE PARTICULAR DE ENSINO ACERCA DO PAPEL DO PSICÓLOGO ESCOLAR
}

\section{THE SOCIAL REPRESENTATION OF STUDENTS FROM PRIVATE EDUCATION ON THE ROLE OF SCHOOL PSYCHOLOGIST}

\author{
Isaura Santana Costa Carvalho* \\ Maria Veracy Moreira de Souza
}

\section{RESUMO}

Esta pesquisa teve como objetivo compreender a representação social que os alunos de escolas da rede particular de ensino têm acerca do papel do psicólogo escolar. Os dados foram obtidos por meio de entrevistas realizadas com 9 alunos do $7^{\circ}, 8^{\circ}$ e $9^{\circ}$ ano. Os resultados colhidos constataram que os alunos percebem o psicólogo escolar basicamente como um profissional que está capacitado a solucionar conflitos. Assim, cabe ao psicólogo escolar delimitar melhor seu campo de atuação para uma melhor compreensão da sua prática profissional.

Palavras-chave: estudantes; psicólogo escolar; representação social.

\section{ABSTRACT}

This article aims at understanding the social representation that private school students have of the role of a school psychologist. The data included interviews carried out with 9 high school students from the $7 \mathrm{~h}, 8^{\text {th }}$ and $9^{\text {th }}$ grades. The interviews have shown that the students see the school psychologist as a professional whose sole ability is to solve problems. Thus, it is the school psychologist responsibility to better delimit their scope of action in order to produce a clearer understanding of their profession.

Keywords: students; school psychologist; social representation.

\footnotetext{
* União Metropolitana de Educação e Cultura (UNIME). Itabuna, (BA), Brasil. isacosta30@hotmail. com; União Metropolitana de Educação e Cultura (UNIME). Itabuna, (BA), Brasil. veracymoreira@ hotmail.com
} 


\section{INTRODUÇÃO}

A Associação Brasileira de Psicologia Escolar e Educacional (ABRAPEE), tem como entendimento que psicólogos escolares e educacionais são profissionais que, em virtude de sua formação universitária em psicologia e práticas subseqüentes nas áreas escolar e/ou educacional, trabalham visando melhorar o processo ensinoaprendizagem no seu aspecto global (cognitivo, emocional, social, motor), através de serviços oferecidos a indivíduos, grupos, famílias e organizações. Portanto, a Psicologia dentro da Escola encontra-se engajada ao processo pedagógico, funcionando como apoio da coordenação.

Durante várias décadas, a atuação do Psicólogo Escolar esteve limitada à avaliação e ao diagnóstico de crianças nas instituições de ensino, sobretudo, na criação de critérios para classificar as que não estavam adaptadas aos ditos padrões ideais estabelecidos pela classe social dominante nos diferentes períodos históricos. Os rótulos atribuídos a elas apenas mudaram de nome: inicialmente classificadas em normais e anormais, depois crianças problema e, posteriormente, deficientes ou carentes.

Na década de 80, foi iniciado um movimento de análise crítica da atuação do psicólogo escolar, com base no Materialismo Histórico Dialético formulado por Karl Marx, onde os problemas de aprendizagem passaram a ser vistos como um fenômeno complexo, constituído socialmente, sendo que sua análise deveria levar em conta aspectos históricos, econômicos, políticos e sociais. Nesse período, ao psicólogo era lançado o desafio de superar a visão técnico-clínica que vinha embasando sua atuação. $\mathrm{O}$ momento era de criar espaços de reflexões com todos os grupos que faziam parte da escola, englobando família, aluno, professores, pedagogos, funcionários e comunidade - considerando a realidade escolar como um todo. Fazia parte também desse contexto discussões e a construção-desconstrução da teoria e prática em psicologia escolar produzida constantemente de forma dialética (LIMA, 2005). Pode-se notar o surgimento de atuações de caráter preventivo, comunitário e envolvendo grupos para toda a comunidade escolar (SANT'ANA et al, 2009).

Ainda hoje, a visão que os alunos têm acerca da atuação do Psicólogo Escolar é pouco focalizada nas pesquisas | nacionais (SANT’ANA et al, 2009). Algumas (CAETANO 1992; NEVES, 1989; SILVA, 1995) indicam apenas a existência de uma representação social do psicólogo, identificando-o como um profissional que exerce as funções de ajuda e orientação. Mesmo sem muitos caminhos em pesquisa sobre, já se pode dizer que a atuação do Psicólogo Escolar pode ser desenvolvida de forma individual ou em grupo, mas sempre em parceria com o educando, a fim de possibilitar uma melhor compreensão dos diversos fatores que interferem nas 
relações e na eficácia do trabalho. Esse profissional deve oferecer informações, discutir medidas para uma melhor qualidade de vida e ensino aos alunos e a todos os serviços oferecidos na escola; contudo, para que o trabalho do Psicólogo possa ser efetivo não se pode descartar o contexto familiar, social, afetivo-emocional e, principalmente, a colaboração da equipe, família e aluno.

Vale ressaltar que, por muito tempo, as verdadeiras atribuições do psicólogo escolar ficaram desconhecidas ou mesmo confundidas - o que proporcionou uma visão inadequada dos profissionais que trabalhavam junto com ele. Entretanto, as configurações do papel deste profissional foram estabelecidas e, hoje, podemos asseverar que suas atribuições estão melhor definidas e envolvem reflexões críticas sobre a instituição, bem como do processo ensino-aprendizagem, da relação professor-aluno e todas as mudanças sociais que estão ocorrendo.

De acordo com Witter (1997) e Maluf (1994), o psicólogo escolar, no exercício da sua função, é determinado pela influência de variáveis oriundas da sua própria formação e opção teórica, com possibilidade de atuação como Especialista Educacional aplicando conhecimentos psicológicos na escola; sobretudo no que diz respeito ao processo ensino-aprendizagem, ao desenvolvimento humano, às relações interpessoais e à integração família-comunidade-escola - através da atuação de equipe interdisciplinar. Esse também é capaz de assumir o papel de Assessor e Consultor prestando serviços diretos e indiretos aos agentes educacionais e orientando programas de apoio administrativos e educacionais como profissional independente. Outra função que pode ser desempenhada pelo Psicólogo Escolar é a de Ergonomista, pois pode desenvolver estudos e analisar as relações homemambiente, físico-material no que se refere ao processo ensino-aprendizagem e produtividade educacional. Como Ecólogo, colabora desenvolvendo programas visando à qualidade de vida e aos cuidados indispensáveis às atividades acadêmicas. Na função de Modificador de Comportamento, este profissional atua na implantação de programas para alterar comportamentos e hábitos mal adaptados ao contexto escolar. Como Avaliador age não somente na avaliação do processo ensino-aprendizagem - usando e validando instrumentos e testes psicológicos adequados e fidedignos, mas também fornecendo subsídios para o replanejamento e reformulação do plano escolar, ajustes e orientações à equipe escolar e, por último, podemos dizer que o Psicólogo Escolar pode ser Pesquisador coletando dados sobre a realidade da escola visando desenvolver o conhecimento científico.

Por outro lado, uma das maiores dificuldades encontradas pelo Psicólogo Escolar é o de se estabelecer como parte efetiva da equipe multidisciplinar dentro da escola, ou seja, se caracterizar como funcionário da escola e não só prestador de serviços esporádicos. 
Para que as diversas funções, que competem ao profissional que desempenhe o papel de psicólogo escolar, sejam devidamente definidas e aplicadas, faz-se necessária a inserção deste na equipe como condição de representante de uma classe que deseja promover as mudanças nos processos educativos, possibilitando que vivências escolares possam ser aperfeiçoadas, de forma que os problemas surgidos possam ser amplamente discutidos e a busca e solução para os mesmos possam ser compartilhadas com a equipe como um todo.

Sabendo que a escola é um espaço onde se tecem relações com diferentes expectativas que variam de acordo com as funções sociais/escolares e os papéis que cada um ocupa na dinâmica escolar, a teoria das representações sociais contribui para se perceber e esclarecer criteriosamente esses saberes coletivos - partilhados por um grupo e, nem sempre, explícitos ou claros.

O conceito de representação social apresenta-se como elemento central para esclarecimento desta proposta de estudo, uma vez que visa identificar as concepções que os alunos de escolas da rede particular de ensino têm acerca do papel do Psicólogo Escolar, de forma a compreender o processo de construção dessas representações e verificar se as concepções apresentadas pelos alunos correspondem ao que se espera da prática desse profissional.

De acordo com Moscovici (1981, apud SÁ; 1996, p.24), pode-se entender representações sociais como um conjunto de conceitos, afirmações e explicações originadas no decurso do cotidiano, no decurso das comunicações interindividuais. Elas são equivalentes em nossa sociedade, aos mitos e sistemas de crenças das sociedades tradicionais; elas podem até mesmo ser vistas como uma versão contemporânea de senso comum.

Desta forma, as representações sociais como teorias do senso comum têm particularidades e fazem emergir uma identidade de grupo a partir das experiências vividas nele. Tais representações podem ser de um determinado grupo - quando as práticas, vivências, classe social, são elementos partilhados pelo mesmo. Tal grupo passa, então, a se caracterizar pelas representações partilhadas por seus membros em razão do grau de adesão ou não aos tipos de opiniões e são ancoradas, coletivamente, apesar das heterogeneidades individuais.

Os fatores culturais e as diferentes formas de viver influenciam muito na escolha dos elementos que aparecem como estruturadores da representação. A variedade e a diversidade contextual são fortes elementos na conceituação dos olhares em representação social. A organização dessas teorias da realidade pode se relacionar com outras visões que o aluno tem a respeito do psicólogo fora do contexto escolar (MENIN, 2004).

Acredita-se que as representações são concretizadas e transformadas a partir da ação, apesar da existência de contradições entre o pensamento e as práticas. 
Privilegia-se, dessa forma, o processo social no qual as representações se formam e se transformam, considerando a função reprodutivista da ideologia em ações e seus mecanismos cognitivos (OLIVEIRA et al, 2001 apud OLIVEIRA, ALVARENGA \& SIQUEIRA, 1998).

Por fim, é possível dizer que o conhecimento das representações externadas pelos alunos no contexto de atuação do Psicólogo Escolar resultará num mapeamento da realidade identificada; portanto, é relevante compreender como os mesmos percebem o papel do psicólogo.. Em virtude disso, o presente estudo buscou conhecer o que pensam os estudantes do ensino fundamental do $7^{\circ}$ ao $9^{\circ}$ ano de três escolas da rede particular de ensino da cidade de Itabuna acerca da atuação do psicólogo escolar.

\section{MÉTODO}

A metodologia utilizada foi a qualitativa, por proporcionar ao pesquisador o contato direto com os fatos e gerar, a partir da dinâmica de interação social, um novo conhecimento (LIMA et al. 1999 apud CRUZ NETO 1994), sendo também um estudo de campo, uma vez que privilegiou um conhecimento mais amplo e detalhado acerca do tema estudado.

\section{PARTICIPANTES E PROCEDIMENTOS}

Participaram desta pesquisa estudantes do ensino fundamental de três escolas da rede particular de ensino da cidade de Itabuna, divididos da seguinte maneira: 3 alunos do $7^{\circ}$ ano, 3 alunos do $8^{\circ}$ ano e 3 alunos do $9^{\circ}$ ano totalizando 9 pesquisados. Foram utilizados como critério de inclusão: 1) estar cursando regularmente entre o sétimo e o nono ano do ensino fundamental; 2) ter conhecimento da existência do psicólogo escolar na escola em que estuda. Como critério de exclusão: 1) alunos portadores de deficiência física ou mental que impeça sua comunicação.

Foi solicitada à direção das escolas autorização para que fossem realizadas as entrevistas e apresentado o Termo de Consentimento Livre Esclarecido (TCLE), contendo os objetivos e normas éticas da pesquisa, com o fim de realização de estudos naquelas unidades de ensino. Disponibilizou-se, também, um espaço silencioso e tranquilo para que os alunos pudessem ser entrevistados. 


\section{COLETA DE DADOS E MATERIAL}

A coleta de dados foi feita em 3 escolas nos dias 29/10/10, 03 e 05/11/2010. Utilizou-se o recurso de entrevista semi-estruturada, o qual, segundo (Lima et al (1999 apud HAGUETTE, 1995), é um processo de interação social onde o entrevistador tem a finalidade de obter informações do entrevistado, através de um roteiro contendo tópicos em torno de uma problemática central, privilegiando, ainda, a obtenção de informações através da fala individual.

O roteiro de entrevista constitui-se de oito questões: (1) Você tem conhecimento do tipo de trabalho que o Psicólogo realiza dentro desta escola? (2) O que a figura do psicólogo representa para você? (3) Você consegue identificar as principais situações em que a presença do psicólogo se faz necessária? (4) Como o psicólogo pode contribuir nas diversas situações existentes na escola? (5) Se você fosse o diretor desta escola o psicólogo seria um profissional que contrataria, por quê? (6) Você já acompanhou alguma circunstância dentro da escola em que a presença do psicólogo fosse essencial para resolver alguma situação específica? (8) O que você entende por psicologia escolar? Para registrar as informações, foi utilizado gravador - mediante assinatura do TCLE (Termo de Consentimento Livre e Esclarecido).

\section{RESULTADOS E DISCUSSÕES}

No que concerne à primeira questão, observou-se que vários alunos fizeram avaliações de caráter geral, demonstrando uma percepção distorcida do papel do psicólogo escolar. Muitas respostas se basearam na ideia de que o psicólogo é uma pessoa que somente ajuda, evidenciando, assim, o desconhecimento das diversas atribuições deste profissional. Diante das respostas: "...sim o psicólogo é importante por que dá apoio dentro da escola e ao aluno para trabalhar em casa com os pais..." e mais," ...sim, ajuda os adolescentes que nessa época tem problema, ela ajuda acalmar...", como também, "...ajuda a gente a se socializar, quando acontece um problema na sala o psicólogo ajuda a resolver...", constatouse que existe uma grande carência de informação por parte dos estudantes sobre o tipo de trabalho desenvolvido pelo psicólogo dentro da escola, contrariando o que foi citado por Sant'ana (2009 apud GUZZO, 1999, 2005), sobre o psicólogo tem um papel fundamental na melhoria da qualidade das relações escolares, visando autonomia e desenvolvimento da capacidade crítica do aluno, tendo em conta elementos social e políticos presentes na realidade onde os estudantes estão inseridos. 
A segunda questão permitiu aos alunos manifestarem a representação social do papel do psicólogo escolar como solucionador de conflitos. Ex.: "...sempre que acontece alguma briga o psicólogo resolve...", o que tem sido percebido por outros autores em várias pesquisas, que destacam a necessidade de o psicólogo favorecer o processo ensino-aprendizagem, mas fazem críticas à perspectiva de o trabalho psicológico estar associado, principalmente, à intervenção com os chamados alunosproblema, conforme citado por Sant'ana et al (2009). Corroborando esta ideia, 100\% dos alunos entrevistados nesta pesquisa responderam que a figura do psicólogo representa para eles um solucionador de problemas. A mesma temática de resposta foi dada para a terceira questão. Ex.: "...nas brigas sem motivos o psicólogo é necessário para acalmar...", ou "... quando por exemplo tem uma briga entre alunos, para desfazer a raiva", "...nas pessoas sem controle, que briga sem motivo".

No que diz respeito à questão que aborda as contribuições do psicólogo no contexto escolar, as respostas mais frequentes foram de que ele: conversa, apoia, aconselha, acalma e passa confiança. Ex.: "...o psicólogo tem essa magia de ajudar, acalmar, deixar as pessoas tranduiilizadas", "...pode dar conselho tentar fazer que o aluno se abra e ter confiança", "...com uma boa conversa".

Ao que foi perguntado na $5^{\text {a }}$ questão, todos responderam que contratariam o psicólogo escolar por acreditarem no seu papel de ajudar os alunos em suas dificuldades, conforme os relatos a seguir descritos: "...sim acho importante por que ajuda as pessoas tímidas a fazerem amigos...", "...sim o psicólogo é fundamental em qualduer escola".

Nas situações abordadas na $6^{\mathrm{a}}$ questão, onde se questionou a circunstância em que a presença do psicólogo foi mais necessária, as situações de conflito predominaram como resposta. Ex.: "...nas discussões dos alunos", "... as de brigas que os meninos se espancaram...", "...na $\sigma^{a}$ série a gente tinha um colega que se transformava, brigava, ia pra cima da gente com objetos que podiam machucar e ninguém conseguia controlar".

O entendimento que os alunos têm por psicologia escolar gira em torno de: Ex.: "...eu acho que é uma pessoa que vai estar te ajudando, dando conselhos, até em notas"; "... a psicologia escolar é um ensinamento muito importante e que pode ajudar muito"; ".. é uma forma de ajudar os alunos na escola"; "... deve ser uma professora dando conselhos de psicologia para os alunos".

No contexto das respostas, observou-se em menor escala, outras formas de percepção do aluno com relação ao papel do psicólogo escolar, sendo o mesmo visto como colaborador no processo de aprendizagem e socialização, namoro na escola, bullying, hiperatividade e, até mesmo, como uma figura mágica que tem poder para resolver tudo.

Percebe-se que, confirmando o que foi pesquisado por Sant'ana (2009) e Guzzo $(1999 ;$; 2005), o desvio que os alunos têm na visão do verdadeiro papel do psicólogo denota uma grande falta de informação, percepção ainda baseada em 
ideias do senso comum e estereótipos difundidos pela sociedade que vê o psicólogo como possuidor de capacidade de resolver todos os problemas. Assim, o psicólogo escolar não é percebido em sua atividade social e política, o que fica evidenciado no esboço da tabela abaixo, onde estão elencadas as principais respostas fornecidas pelos alunos acerca da representação social do papel do psicólogo escolar.

Tabela 1. Classe das respostas apresentadas pelos alunos do $7^{\circ}, 8^{\circ}$ e $9^{\circ}$ ano sobre o papel do psicólogo na escola.

Classe de Respostas

Solucionador de Conflitos

Pessoa que ajuda e dá conselhos

Ajuda a melhorar as notas

Pessoa que possui magia para ajudar a acalmar

\section{CONSIDERAÇÕES FINAIS}

A pesquisa constatou a visão distorcida dos alunos acerca do papel do psicólogo escolar. Esta constatação pode ser confirmada com dados da literatura, demonstrando que, por muito tempo, as verdadeiras atribuições deste profissional ficaram desconhecidas ou mesmo confundidas, construindo, assim, uma visão inadequada do seu papel.

A falta de delimitação do seu campo de atuação, bem como a falta de entendimento de outros profissionais da área de educação em relação ao trabalho a ser desempenhado pelo psicólogo contribuiu, também, para a construção de uma imagem mesclada do psicólogo escolar, muitas vezes, entrando em cena como figura ameaçadora e, em outros momentos, como solucionador de problemas imediatos (MENEZES et al, 2007).

De acordo com Morin, (2000. p. 99) não se pode reformar a instituição sem a prévia reforma das mentes, mas não se podem reformar as mentes sem uma prévia reforma das instituições. Dentro deste enfoque, enquanto os educadores e demais profissionais da escola entenderem como principal atribuição do psicólogo escolar o atendimento ao aluno-problema, a atuação desse profissional continuará restrita.

É importante lembrar que, na medida em que o Psicólogo delimita seu espaço dentro da instituição escolar, mais fácil será para ele sair da condição 
desconfortável de bombeiro - restrito à atuação de apagar incêndios, somente sendo convocado nos momentos em que os conflitos se estabelecem; entretanto, os registros evidenciam que este lugar mais amplo ainda não se consolidou, mas está em construção. Percebem-se já, evidências da importância permanente da figura do psicólogo, promovidas pelo exercício de uma prática, onde as novas perspectivas de intervenção e de compreensão da realidade são vislumbradas.

Cabe ao profissional de psicologia escolar empreender esforços no sentido de confirmar o seu campo de atuação de forma bem delimitada, a fim de ser reconhecido em sua função específica dentro da instituição escolar.

Dessa forma, para que haja uma modificação dessa percepção é necessária a construção de posturas preventivas e esclarecedoras por parte do psicólogo, cabendo ao mesmo esforço e habilidade na elaboração de ações que o aproximem da realidade dos estudantes.

Acredita-se que estudos abordando as várias representações sociais acerca do papel do psicólogo escolar podem contribuir para uma maior compreensão da atuação desse profissional, ao mesmo tempo em que esclarece percepções distorcidas dos estudantes no âmbito educativo.

Os dados obtidos por esta pesquisa demonstram a necessidade de informações e práticas concretas por parte do psicólogo escolar, que possam desmistificar sua atuação, de forma que proporcione aos alunos compreenderem que o mesmo não está na instituição escola apenas como solucionador de conflitos. Desse modo, a divulgação das informações constantes neste artigo permite aclarar as distorções e ajudar a construir uma imagem mais condizente com a real função do psicólogo escolar.

\section{REFERÊNCIAS BIBLIOGRÁFICAS}

LIMA, A. O. M. N. (2005) Breve histórico da psicologia escolar no Brasil. Psicologia Argumento, Curitiba, v. 23, n. 42 p. 17-23. Disponível em: www2.pucpr.br/reol/ index.php/PA?dd $1=173 \& d d 99=$ pdf. Acesso em: 10 outubro 2010 .

GUZZO, R. S. (1999) Novo paradigma para formação e atuação do psicólogo escolar no cenário educacional brasileiro. Psicologia Escolar. LDB e educação boje. Campinas, p. 131-144. Disponível em: http://pepsic.bvsalud.org/scielo.php

GUZZO, R. S. L. (2005) Escola amordaçada: compromisso do psicólogo com este contexto. In A. M. Martinez (Org.), Psicologia escolar e compromisso social (pp. 17-29). Campinas, SP: Alínea. 
MALUF, M. R. (1994) Formação e atuação do psicólogo na educação: dinâmica de transformação. In Conselho Federal de Psicologia. Psicólogo Brasileiro: práticas emergentes e desafios para a formação. São Paulo, Casa do Psicólogo.

MENEZES, C.L: CARVALHO, K. L.: ATAÍDE, P. C. Q.: BELFORT, S. F.: CASSOTE, S. B. (2007) Mitos e verdades sobre a atuação do Psicólogo Escolar: A visão deste pelos profissionais e alunos de uma instituição de ensino privada em Manaus. Licenciatura em Psicologia.

MENIN, M.S.S.; CARBONE, R.A. (2004) Injustiça na escola: representações sociais de alunos do ensino fundamental e médio. Edição e pesquisa. vol $30 \mathrm{n}^{\circ} 2$ p.251-270 maio/ago.2004. Disponível em: http://www.scielo.br/pdf/ep .

MORIN, Edgar. (2000) A cabeça bem feita. $8^{a}$ Ed. Trad. Eloá Jacobina. Rio de Janeiro: Bertrand Brasil.

OLIVEIRA, D.C. et al. (2001) Futuro e liberdade: o trabalho e a instituição escolar nas representações sociais de adolescentes. Estudos de psicologia. vol 6 n 2 p. 245258. Disponível em: http://www.scielo.br/pdf/epsic .

SÁ, C. P. de. (2001) A construção do objeto de pesquisa em representações sociais. Rio de Janeiro: edUERJ, p.197.

SANT'ANA, M. I. et al. (2009) Psicólogo e escola: a compreensão de estudantes do ensino fundamental sobre esta relação. Psicologia escolar educacional. vol.13 $\mathrm{n}^{\circ} 1$ Campinas. Disponível em: http://pepsic.bvs-psi.org.br/scielo.php Acesso em: 02 novembro 2010

WITTER, G. P. (1977) O Psicólogo Escolar: Pesquisa e Ensino. Tese de Livre Docência. Instituto de Psicologia da USP. São Paulo.

Recebido: 29/11/2010

Aceito: 11/10/2011 